\title{
Circadian course of the P300 ERP in patients with amyotrophic lateral sclerosis - implications for brain-computer interfaces $(\mathrm{BCl})$
}

Helena Erlbeck', Ursula Mochty ${ }^{2}$, Andrea Kübler ${ }^{1}$ and Ruben G. L. Real ${ }^{1,3^{*}}$

\begin{abstract}
Background: Accidents or neurodegenerative diseases like amyotrophic lateral sclerosis (ALS) can lead to progressing, extensive, and complete paralysis leaving patients aware but unable to communicate (locked-in state). Brain-computer interfaces $(\mathrm{BCl})$ based on electroencephalography represent an important approach to establish communication with these patients. The most common BCl for communication rely on the P300, a positive deflection arising in response to rare events. To foster broader application of $\mathrm{BCls}$ for restoring lost function, also for end-users with impaired vision, we explored whether there were specific time windows during the day in which a P300 driven BCI should be preferably applied.
\end{abstract}

Methods: The present study investigated the influence of time of the day and modality (visual vs. auditory) on P300 amplitude and latency. A sample of 14 patients (end-users) with ALS and 14 healthy age matched volunteers participated in the study and P300 event-related potentials (ERP) were recorded at four different times $(10,12$ am, 2, \& 4 pm) during the day.

Results: Results indicated no differences in P300 amplitudes or latencies between groups (ALS patients V. healthy participants) or time of measurement. In the auditory condition, latencies were shorter and amplitudes smaller as compared to the visual condition.

Conclusion: Our findings suggest applicability of EEG/BCI sessions in patients with ALS throughout normal waking hours. Future studies using actual $\mathrm{BCl}$ systems are needed to generalize these findings with regard to $\mathrm{BCl}$ effectiveness/ efficiency and other times of day.

Keywords: Amyotrophic Lateral Sclerosis, ALS, P300, Auditory, Visual, Brain computer interface, BCI

\section{Background}

For people with advanced neurodegenerative diseases or in states of severely reduced mobility due to accidents or illness, a brain-computer-interface (BCI) might be the only means to communicate with their environment. A BCI uses brain signals most often recorded with electroencephalography (EEG) and converts them into control signals replacing, restoring, or enhancing the natural

\footnotetext{
* Correspondence: ruben.real@med.uni-goettingen.de

${ }^{1}$ Institute of Psychology, University of Würzburg, Würzburg, Germany

${ }^{3}$ Institute of Medical Psychology and Medical Sociology, University Medical Center Göttingen, Waldweg 37, 37073 Göttingen, Germany

Full list of author information is available at the end of the article
}

output of the central nervous system the patient (enduser of $\mathrm{BCI}$ technology) is no longer able to perform [1] (see also the BNCI H2020 roadmap). For example, the so-called P300-speller, a BCI application to allow the spelling of words on a computer screen, is one of the most commonly used devices and has been applied in healthy participants as well as in patients [2-6]. It relies on a positive deflection about $300 \mathrm{~ms}$ after a rare stimulus in a visual oddball paradigm comprising irrelevant frequent and relevant rare (target) stimuli (P300 ERP, [7, 8]).

In addition to the visually based P300 speller, there have also been efforts to design a $\mathrm{BCI}$ solely relying on

\section{Biomed Central}


auditory stimuli for users with impaired vision or eye gaze control [9-15]. Until recently, auditory BCIs faced the problem of a limited amount of classes, i.e. differentiable choices they present to the end-user of BCI [16]. However, Höhne and Tangermann introduced the CharStreamer system, which is based on 30 spoken sounds of letters and actions and demonstrated a competitive spelling speed. Halder and colleagues [17] showed that even patients with severe motor impairment including those with amyotrophic lateral sclerosis (ALS) could control an auditory speller with high accuracy provided several training sessions.

Patients with neurodegenerative diseases, specifically those diagnosed with ALS are a major target group for BCIs. ALS affects neurons of the motor system and beyond, leading to progressing muscle weakness and atrophy [18]. In its late stages, patients are left unable to move or breathe while being fully aware of themselves and the environment. Thus, for these patients a BCI solely relying on brain activity may be the only way to communicate their thoughts and wishes.

In general, BCI performance is not only influenced by soft- and hardware factors, e.g. choice of equipment and classifiers, but also by physiological and psychological variables related to the generation of the EEG input signal [19]. For example, the frequently used P300 ERP depends on attention and working memory processes $[20,21]$, with reduced attention / high working memory load being associated with lower amplitudes and prolonged latencies [22]. In addition to motor impairment, patients with ALS may also experience respiratory dysfunction, disrupted sleep, and fatigue [23], which in turn may limit attentional and working memory performance [24]. However, it is unclear how relevant these findings are in an applied setting; some studies reporting P300 amplitudes comparable between healthy participants and ALS patients, and others showing reduced P300 amplitudes in patients with ALS [25-27]. Similarly, some studies found prolonged latencies in ALS [27, 28], while others revealed no such difference $[29,30]$.

Given the objective of $\mathrm{BCIs}$ to become a viable means for long-term home based communication in patients with ALS, a second potentially important factor concerns the sensitivity of attention and working memory to circadian variation. Whereas behavioral measures of these processes generally indicate declining performance throughout the day [31], it is unclear whether these changes are also associated with reduced amplitudes/ prolonged latencies in the P300 ERP. Some studies of healthy participants suggest sensitivity of the P300 to time of day, whereas other studies found no such an effect [32-35]. In addition, and despite its potential importance, no information on the sensitivity of the P300 to time of day is available from patients with ALS.
Finally, the factor of modality may become relevant when evaluating the suitability of a BCI for ALS patients. For example, there is evidence that -in healthy participants-, the P300 is influenced by modality, with smaller amplitudes and shorter latencies in the auditory domain [36] (but see [37]). Although vision is usually unaffected by ALS, some late stage patients are easily exhausted when using vision based communication devices. For these patients, reliance on the auditory modality may be one of the few alternatives left [38]. Thus, a systematic comparison of the P300 ERP between modalities and time of day is warranted, as this information may be important for researchers when scheduling EEG/BCI sessions and other psychophysiological experiments.

To provide such data, we recorded visual and auditory P300 in patients diagnosed with ALS and age matched healthy participants at four different time points within 1 day in their homes. Specifically, we hypothesized that

(1)there is a decline in P300 amplitudes and an increase in P300 latencies over time (main effect of time of the day).

(2)the effect of the daytime is stronger in ALS patients than in healthy controls (group $x$ time interaction).

Data presented in this paper were taken from Ursula Mochty's dissertation [39] and reanalyzed.

\section{Methods \\ Participants}

A sample of 14 ALS patients and 14 age and sex matched healthy control subjects participated in the study. We only included ALS patients who were still able to communicate a "Yes" or "No" answer in any modality, thus, no ALS patients in the complete locked-in state were included. All participants had normal or corrected to normal vision. ALS patients were between 40 and 73 years old $(M=67.93, S D=10.46)$, healthy participants were between 38 and 79 years of age $(M=58.07$, $S D=10.69 ; t=-0.034, D F=26, p=.972)$. All ALS patients were assessed with the revised ALS functional rating scale (ALSFRS-R; [40]). Scores varied between 2 and $36(M=21.79, S D=10.53)$, with lower scores indicating more severe physical impairment.

\section{Procedure and stimuli}

The study was conducted at the participants' home. Participants sat in a comfortable chair with a computer screen in front of them. The experiment consisted of four identical sessions conducted at 10, 12 am, 2 and $4 \mathrm{pm}$. Each session lasted $12 \mathrm{~min}$ and started with the recording of $4 \mathrm{~min}$ of resting EEG, followed by EEG recording during a visual $(4 \mathrm{~min})$ and auditory oddball 
(4 min). During oddball paradigms, participants were instructed to silently count the deviant stimuli.

\section{Auditory oddball}

Auditory stimuli were 160 standard $(1000 \mathrm{~Hz})$ and 40 deviant $(2000 \mathrm{~Hz})$ tones (rectangular pulse of $50 \mathrm{~ms}$ duration) presented in pseudo-random order with the restriction that any two deviant tones were separated by at least one standard tone. Stimulus onset asynchrony (SOA) was $1200 \mathrm{~ms}$ with a random latency jitter of $\pm 0.15 \mathrm{~s}$ to avoid habituation to a certain SOA [41].

\section{Visual oddball}

Visual stimuli were short $(50 \mathrm{~ms})$ presentations of the letters " $\mathrm{H}$ " (40 times, deviant) and "S" (160 times, standard) in white font $(120 \mathrm{pt})$ on a black background in the centre of a computer monitor [42]. Stimulus onset asynchrony (SOA) was $1.2 \pm 0.15 \mathrm{~s}$ (see above).

\section{Data acquisition}

EEG was recorded using a g-tec USB amplifier (g-tec, Schiedlberg, Austria) with a sampling rate of $256 \mathrm{~Hz}$ (bandpass filter: 0.01 and $30 \mathrm{~Hz}$ ) from 16 electrodes placed at Fp1, Fp2, F3, Fz, F4, T7, C3, Cz, C4, T8, CP3, CP4, P3, Pz, $\mathrm{P} 4$ and $\mathrm{Oz}$ referenced to the right-earlobe (ground at left mastoid). Impedances were kept below $5 \mathrm{k} \Omega$.

\section{Data processing and statistical analysis}

Offline, EEG was epoched into $900 \mathrm{~ms}$ long intervals beginning from $-100 \mathrm{~ms}$ before the start of a stimulus, corrected for eye movements [43], and aligned to the $100 \mathrm{~ms}$ long pre-stimulus baseline. Trials with voltages exceeding $\pm 60 \mu \mathrm{V}$ were rejected as artifacts, remaining trials averaged per condition, and the difference obtained (deviant - standard, see Fig. 1). This difference between the curves elicited by the standard versus the deviant represents the decisive factor for $\mathrm{BCI}$ classifiers to differentiate responses by the participants. In the auditory condition, peak positive amplitudes and latencies during the analysis interval ranging from 290 to $350 \mathrm{~ms}$ post stimulus onset were detected and exported for statistical analysis. For the visual condition, the interval lasted from 300 to $600 \mathrm{~ms}$ post stimulus onset. EEG data analysis was performed with Brain Vision Analyzer (Brain Products GmbH, Gilching, Germany).

Amplitudes and latencies were analyzed at midline electrodes $(\mathrm{Fz}, \mathrm{Cz}, \mathrm{Pz})$ using repeated measures ANOVAs with within-subject factors time (10, $12 \mathrm{am}, 2,4 \mathrm{pm})$, region (frontal, central, parietal), modality (auditory, visual) and the between-subjects factor group (patients with ALS, healthy participants), and we report GreenhouseGeisser-corrected p-values (after Mauchly's Test). Effect sizes are reported as eta-square $\left(\eta^{2},[44]\right)$, and Cohen's d [45]. Marginal means [46] with degrees of freedom based on the underlying ANOVA model were used for follow-up analysis and p-values of post hoc tests were Tukey corrected for multiple comparisons. Inspection of amplitudes (Tukey boxplots, $\mathrm{k}=1.5,[47]$ ) indicated extremely high values for two participants in the patient sample, which were therefore excluded from all amplitude and latency analyses. Similarly, inspection of the distribution of latencies indicated potentially outlying values for five patients with ALS and five healthy participants. Since we deemed it unfeasible to exclude such high a number of participants, the results of the repeated measures ANOVA on latencies was replicated using a permutation based repeated measures ANOVA-equivalent, which confirmed the results of the parametric ANOVA.

The correlation between ALSFRS-R and P300 mean amplitude/latency was based on the respective averaged Fisher Z-transformed Spearman correlation coefficients and evaluated using a t-test. EEG curves in Fig. 1 were $10 \mathrm{~Hz}$ butterworth low-pass filtered for visual presentation. Statistical analyses were performed in R [48] using the ez [49], lsmeans [50], ImPerm [51], and signal packages [52].

\section{Results \\ P300 amplitude}

Analysis of P300 amplitudes indicated significant main effects of modality $\left(F(1,24)=7.23, p=.013, \eta^{2}=.07\right)$ and region $(F(2,48)=17.62, p<.001, \eta 2=.06$ see Fig. 2$)$, and a marginally significant interaction of group, time, modality, and region $(F(6144)=2.17, p=.049, \eta 2=.001)$. Follow-up analysis indicated that amplitudes in the auditory modality were on average smaller than in the visual modality $(t=-2.69, D F=24, p=.013, \mathrm{~d}=-.22)$, and amplitudes at $\mathrm{Fz}$ were smaller than at $\mathrm{Cz}(t=-4.90$, $D F=48, p<.001, \mathrm{~d}=-0.48)$ and $\mathrm{Pz}(t=-5.35, D F=48$, $p<.001, \mathrm{~d}=-0.53)$, but comparable between $\mathrm{Cz}$ and Pz $(t=-0.45, D F=48, p=.894, \mathrm{~d}=-0.04)$. Follow-up analysis (per modality and region) on the interaction of group, time, modality, and region did not reveal significant differences in amplitudes between time of day and group (all $p>.20$ ).

\section{P300 latency}

Analysis of P300 latencies revealed a significant main effect of modality $\left(F(1,24)=119.13, p<.001, \eta^{2}=0.38\right)$, an interaction of modality and region $(F(2,48)=6.07$, $p=.011, \eta^{2}=0.02$, see Fig. 3), but no effects of group, time, or any of their interactions. Follow-up analysis indicated that latencies in the auditory modality were always shorter than in the visual modality at all electrodes (all $p$ $<.001$ ), but the latency difference between the two modalities was larger at Fz than at $\mathrm{Pz}(t=3.48, D F=48, p=.003$, $\mathrm{d}=0.68$ ) with no significant differences between either $\mathrm{Fz}$ and $\mathrm{Cz}$ and $\mathrm{Cz}$ and $\mathrm{Pz}$ (all $p>$.156). 


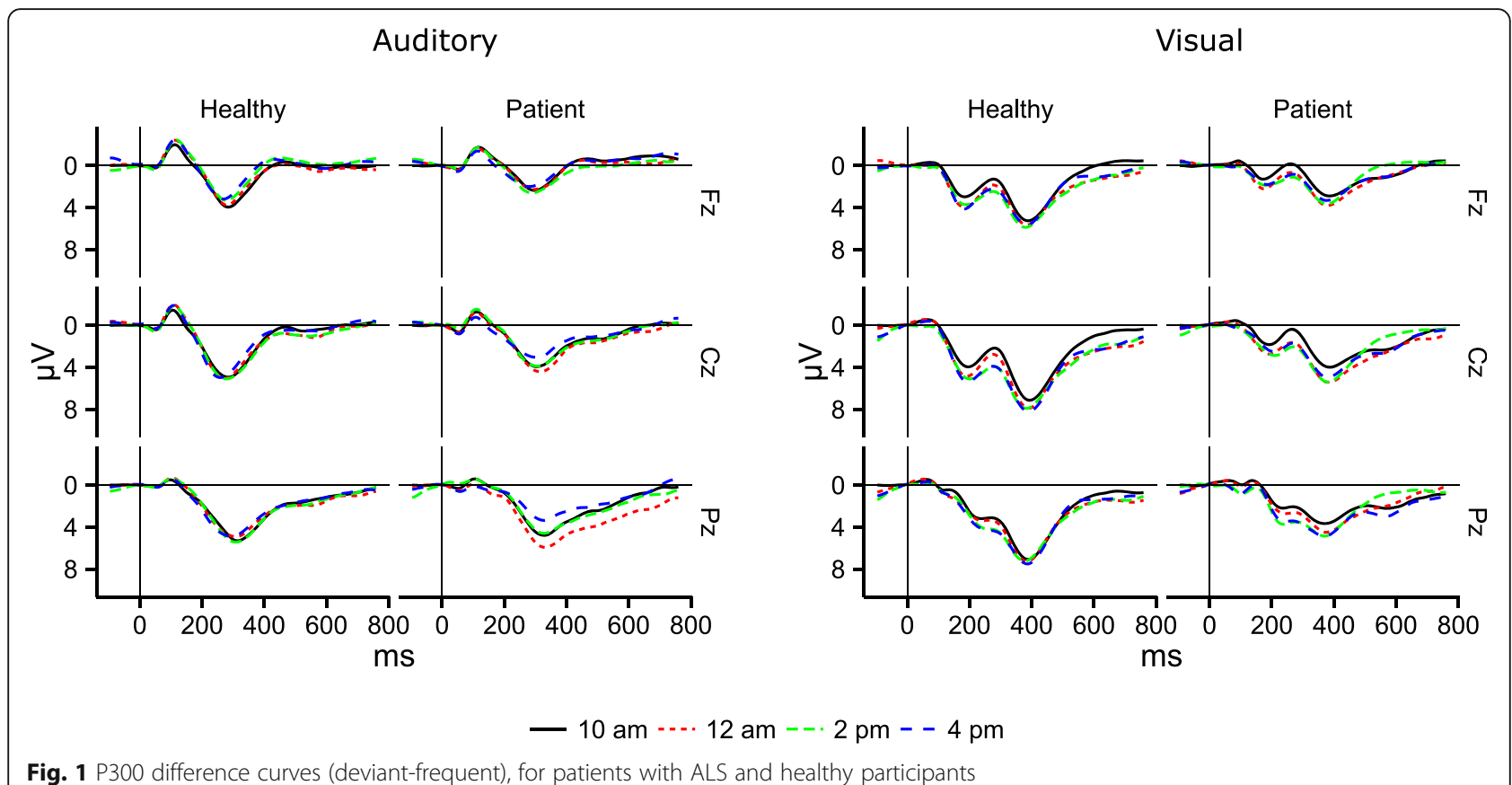

\section{Relation to physical impairment (ALSFRS-R)}

To test for potential interrelations between severity of ALS (ALSFRS-R score) and P300 amplitude/latency, we calculated correlational analyses in the patient sample. Disease severity did not correlate with P300 peak amplitude $(r=.21$, $t=0.68, D F=10, p=.745)$ or latency $(r=-0.09, t=-0.29$, $D F=10, p=.389$ ).

\section{Discussion}

The present study was conducted to investigate whether time of the day and modality (visual vs. auditory) should be considered as factors influencing P300

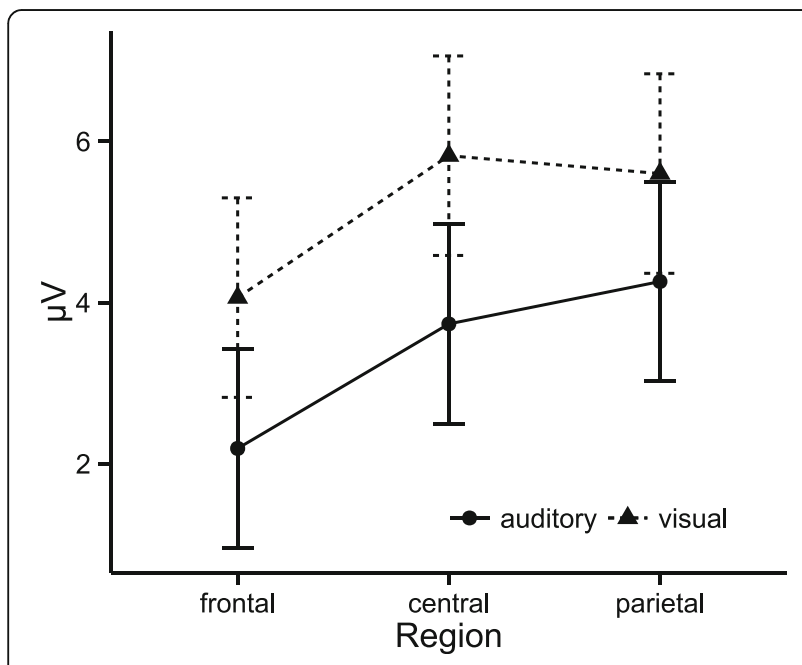

Fig. 2 P300 amplitude across modalities and regions. Error bars represent 95\% confidence intervals amplitude and latency when conducting BCI sessions in patients with ALS.

Our hypotheses predicted a general decline of P300 amplitudes and increased latencies throughout the day, and that this proposed effect would be even more pronounced in patients with ALS. Our analyses neither revealed significant differences in ERP amplitudes/latencies between patients with ALS and healthy participants, nor changes with time of day. Instead, we only found that in the auditory domain, amplitudes were smaller and latencies shorter than in the visual domain. P300 amplitudes in both modalities were more positive at $\mathrm{Cz}$ and $\mathrm{Pz}$ than at $\mathrm{Fz}$.

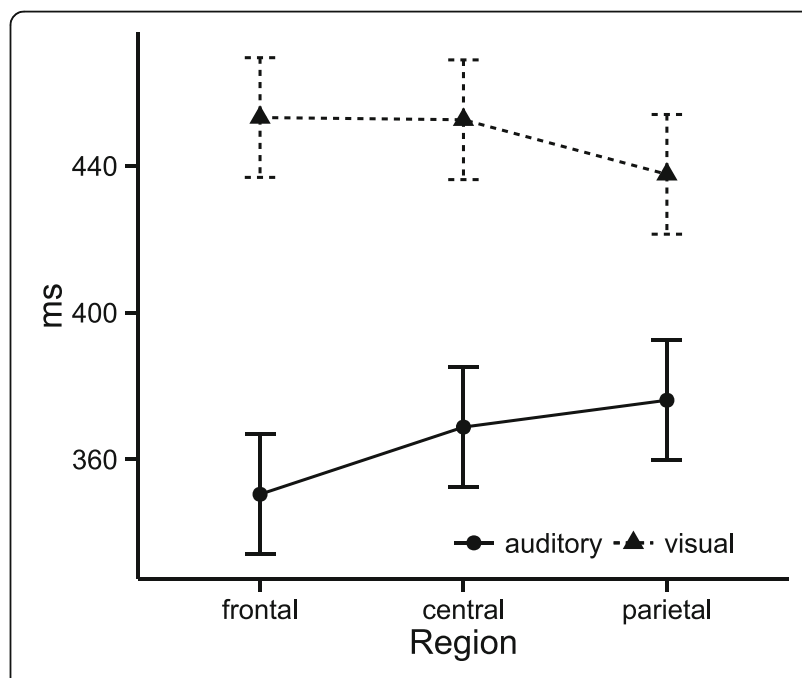

Fig. 3 P300 latencies. Error bars represent 95\% confidence intervals 
These results indicate that in patients with ALS P300 amplitudes comparable to those of healthy participants can be elicited in both modalities, which supports the feasibility of a P300 BCI also in late stage ALS. Although some previous studies obtained similar results [28, 30], this result it still surprising because the majority of studies reports diminished amplitudes and an impaired capacity of sustained attention and working memory in patients with ALS $[25-27,29]$. One possible reason for these comparable amplitudes between ALS patients and healthy participants might be the home environment in which measurements were undertaken. It might be possible that a familiar environment enables the patients to better concentrate on the stimuli and tasks as compared to a laboratory setting.

In a previous study, Wesensten and colleagues [34] found decreases in auditory P300 over the course of the day. However, these findings were challenged by Geisler and Polich [35] who concluded from their study, that auditory P300 amplitudes did not depend on the mere time of day, but on pulse-rate, or body temperature and food intake, both often correlating with time of the day. Food intake, heart rate, or body temperature were not assessed in our study, so no quantification of the effect of these factors can be presented. However, judging from the absence of an effect of time of day, it would appear that their combined effect would be too small to warrant differential scheduling of BCI by time of day. In sum, P300s seem to be elicited irrespective of the time of the day when presented to participants in their home environment.

Although auditory stimulation led to overall smaller P300 amplitudes, amplitudes in ALS patients were still comparable to those of healthy controls. Previous studies have already stressed the need to establish auditory BCIs in ALS patients [53, 54], as in late stages of ALS, patients may also loose reliable control over eye movements. As a consequence, in ALS patients as well as in other behaviorally non-responsive patients, the auditory channel is usually better preserved [55] or might even be the only remaining channel to establish communication [56]. Application of auditory BCIs of different kinds have shown promising results in healthy participants $[9,15,57-59]$ and auditory P300 BCIs based on the tone segregation phenomenon [60] or animal sounds were also brought to patients [59].

\section{Limitations}

Data collection took place at the participants' homes, and analyses were deliberately restricted to midline positions. This was done bearing in mind real-world application scenarios for BCIs, especially with regard to patient's desire for limiting the number of electrodes as much as possible [61]. While similar restricted setups have been shown to be sufficient for achieving BCI control in patients with ALS [62], our results are still only tentative given that classification performance was not evaluated. In addition, we highlight that while time of day is certainly a convenient indicator of patients' fatigue, other, more direct measures could have been used. For example, analyses involving "hours awake", self-reported tiredness, or even physiological indicators of circadian variation [34] as covariates might yield different results, and, hence, such measures might be included in future research. Finally, the low number of patients might limit generalization of results.

\section{Conclusion}

Taken together, the data presented in this study suggest that P300-based BCIs could be applicable in patients with ALS throughout normal waking hours (10 am-4 pm). Patients presented with P300 amplitudes and latencies comparable to those of healthy participants in both, the auditory and the visual domain. Furthermore, there was no correlation between the constraints in physical functioning measured by the ALSFRS-R and P300 physiology. This means that reliable P300 potentials can be elicited also in late stages of the disease, thus preserving the basic requirements for $\mathrm{BCI}$ use. This is also supported by single-case studies which evaluated the usability of BCIs during longterm independent home use [63, 64].

In sum, the present results show the feasibility of P300 ERP recordings in patients with ALS throughout the day, and, hence, the P300's potential usefulness as a BCI input signal in long term independent home use scenarios.

\section{Abbreviation}

ALS: Amyotrophic lateral sclerosis; ALSFRS-R: Revised Amyotrophic Lateral Sclerosis Functional Rating Scale; BCl: Brain computer interface;

EEG: Electroencephalography; ERP: Event related potential; SOA: Stimulus onset asynchrony

\section{Acknowledgments}

This publication was supported by the Open Access Publication Fund of the University of Würzburg, Germany.

\section{Funding}

None.

Availability of data and materials

The data on which our results are based are available from the authors.

Authors' contributions

HE wrote the manuscript, UM and AK designed the experiment, collected the data, analysed the EEG data, and contributed to writing the manuscript, RR carried out and interpreted the statistical analysis, and wrote the manuscript. All authors read and approved the final manuscript.

Competing interests

The authors declare that they have no competing interests.

Consent for publication

Not applicable. 


\section{Ethics approval and consent to participate}

Written informed consent was obtained by all participants or their legal representatives. The study protocol was approved by the Ethical Review Board of the Medical Faculty of the University of Tübingen, Germany.

\section{Author details}

${ }^{1}$ Institute of Psychology, University of Würzburg, Würzburg, Germany. ${ }^{2}$ Institute of Medical Psychology, University of Tübingen, Tübingen, Germany. ${ }^{3}$ Institute of Medical Psychology and Medical Sociology, University Medical Center Göttingen, Waldweg 37, 37073 Göttingen, Germany.

Received: 31 March 2016 Accepted: 9 December 2016 Published online: 07 January 2017

\section{References}

1. Brunner C, Birbaumer N, Blankertz B, Guger C, Kübler A, Mattia D, et al. BNCl horizon 2020: towards a roadmap for the BCl community. Brain-Computer Interfaces. 2015;2:1-10. doi:10.1080/2326263X.2015.1008956.

2. Sellers EW, Ryan DB, Hauser CK. Noninvasive brain-computer interface enables communication after brainstem stroke. Sci Transl Med. 2014;6:257-64. doi:10.1126/scitranslmed.3007801.

3. Farwell $\mathrm{L}$, Donchin E. Talking off the top of your head: toward a mental prosthesis utilizing event-related brain potentials. Electroencephalogr Clin Neurophysiol. 1988;70:510-23. doi:10.1016/0013-4694(88)90149-6.

4. Kleih SC, Kaufmann T, Zickler C, Halder S, Leotta F, Cincotti F, et al. Out of the frying pan into the fire-the P300-based $\mathrm{BCl}$ faces real-world challenges. Progr Brain Res. 2011;194:27-46. doi:10.1016/B978-0-444-53815-4.00019-4.

5. Mak JN, McFarland DJ, Vaughan TM, McCane LM, Tsui PZ, Zeitlin D, et al. EEG correlates of $\mathrm{P} 300$-based brain-computer interface (BCI) performance in people with amyotrophic lateral sclerosis. J Neural Eng. 2012;9. doi:10.1088/ 1741-2560/9/2/026014

6. Nijboer F, Sellers E, Mellinger J, Jordan M, Matuz T, Furdea A, et al. A P300based brain-computer interface for people with amyotrophic lateral sclerosis. Clin Neurophysiol. 2008;119:1909-16. doi:10.1016/j.clinph.2008.03.034.

7. Fabiani M, Gratton G, Federmaier KD. Event-related potentials: methods, theory, and applications. In: Cacioppo JT, Tassinary LG, Berntson GG, editors. Handbook of psychophysiology. 3rd ed. Cambridge: Cambridge University Press; 2007.

8. Sutton S, Braren M, Zubin J, John ER. Evoked-potential correlates of stimulus uncertainty. Science. 1965;150:1187-8. doi:10.1126/science.150.3700.1187.

9. Höhne J, Tangermann M. Towards user-friendly spelling with an auditory brain-computer interface: the CharStreamer paradigm. PLoS One. 2014;9, e98322. doi:10.1371/journal.pone.0098322.

10. Klobassa D, Vaughan T, Brunner P, Schwartz N, Wolpaw J, Neuper C, Sellers E. Toward a high-throughput auditory P300-based brain-computer interface. Clin Neurophysiol. 2009;120:1252-61. doi:10.1016/j.clinph.2009.04.019.

11. Nakaizumi C, Matsui T, Mori K, Makino S, Rutkowski TM. Head-related impulse response-based spatial auditory brain-computer interface. In: Müller-Putz G, Bauernfeind C, Brunner D, Steyrl S, Wriessnegger S, editors. Scherer R, editors; September 16-19; Graz University of Technology. Graz: Verlag der Technischen Universität Graz; 2014. p. 80-3.

12. Sellers EW, Donchin E. A P300-based brain-computer interface: initial tests by ALS patients. Clin Neurophysiol. 2006;117:538-48. doi:10.1016/j.clinph. 2005.06.027

13. Schreuder M, Rost T, Tangermann M. Listen, you are writing! Speeding up online spelling with a dynamic auditory BCI. Front Neurosci. 2011;5:112. doi: 10.3389/fnins.2011.00112.

14. Schreuder E-JM. Towards efficient auditory BCl through optimized paradigms and methods. Berlin: epubl; 2014.

15. Simon N, Käthner I, Ruf CA, Pasqualotto E, Kübler A, Halder S. An auditory multiclass brain-computer interface with natural stimuli: usability evaluation with healthy participants and a motor impaired end user. Front Hum Neurosci. 2015;8:1039. doi:10.3389/fnhum.2014.01039.

16. Höhne J, Schreuder M, Blankertz B, Tangermann M. A novel 9-class auditory ERP paradigm driving a predictive text entry system. Front Neurosci. 2011;5: 99. doi:10.3389/fnins.2011.00099.

17. Halder S, Hammer EM, Kleih SC, Bogdan M, Rosenstiel W, Birbaumer N, et al. Prediction of auditory and visual P300 brain-computer interface aptitude. PLoS One. 2013;8, e53513. doi:10.1371/journal.pone.0053513.

18. Kiernan MC, Vucic S, Cheah BC, Turner MR, Eisen A, Hardiman O, et al. Amyotrophic lateral sclerosis. Lancet. 2011;377:942-55. doi:10.1016/S01406736(10)61156-7.
19. Kübler A, Blankertz B, Müller KR, Neuper C, et al. A model of BCl control. In: MüllerPutz $S$ et al., editors. Proceedings of the 5th International. 2011. p. 100-3. Hg.

20. Polich J, Kok A. Cognitive and biological determinants of P300: an integrative review. Biol Psychol. 1995:41:103-46. doi:10.1016/0301-0511(95)05130-9.

21. Linden DEJ. The P300: where in the brain is it produced and what does it tell us? Neuroscientist. 2005;11:563-76. doi:10.1177/1073858405280524.

22. Polich J. Updating P300: an integrative theory of P3a and P3b. Clin Neurophysiol. 2007;118:2128-48. doi:10.1016/j.clinph.2007.04.019.

23. Strong MJ, Grace GM, Freedman M, Lomen-Hoerth C, Woolley S, Goldstein $\mathrm{LH}$, et al. Consensus criteria for the diagnosis of frontotemporal cognitive and behavioural syndromes in amyotrophic lateral sclerosis. Amyotroph Lateral Scler. 2009;10:131-46. doi:10.1080/17482960802654364.

24. Schneider C, Fulda S, Schulz H. Daytime variation in performance and tiredness/sleepiness ratings in patients with insomnia, narcolepsy, sleep apnea and normal controls. J Sleep Res. 2004;13:373-83. doi:10.1111/j.13652869.2004.00427.x

25. Hammer A, Vielhaber S, Rodriguez-Fornells A, Mohammadi B, Münte TF. A neurophysiological analysis of working memory in amyotrophic lateral sclerosis. Brain Res. 2011;1421:90-9. doi:10.1016/j.brainres.2011.09.010.

26. Hanagasi HA, Gurvit I, Ermutlu N, Kaptanoglu G, Karamursel S, Idrisoglu HA, et al. Cognitive impairment in amyotrophic lateral sclerosis: evidence from neuropsychological investigation and event-related potentials. Cogn Brain Res. 2002;14:234-44. doi:10.1016/S0926-6410(02)00110-6.

27. Paulus K, Magnano I, Piras M, Solinas M, Solinas G, Sau G, Aiello I. Visual and auditory event-related potentials in sporadic amyotrophic lateral sclerosis. Clin Neurophysiol. 2002;113:853-61. doi:10.1016/S1388-2457(02)00082-2.

28. Gil R, Neau J-P, Dary-Auriol M, Agbo C, Tantot AM, Ingrand P. Event-related auditory evoked potentials and amyotrophic lateral sclerosis. Arch Neurol. 1995;52:890-6. doi:10.1001/archneur.1995.00540330068017.

29. McCane LM, Heckman SM, McFarland DJ, Townsend G, Mak JN, Sellers EW, et al. P300-based brain-computer interface (BCI) event-related potentials (ERPs): people with amyotrophic lateral sclerosis (ALS) vs. age-matched controls. Clin Neurophysiol. 2015;126:2124-31. doi:10.1016/j.clinph.2015.01.013.

30. Volpato C, Piccione F, Silvoni S, Cavinato M, Palmieri A, Meneghello F, Birbaumer N. Working memory in amyotrophic lateral sclerosis: auditory event-related potentials and neuropsychological evidence. J Clin Neurophysiol. 2010;27:198-206. doi:10.1097/WNP.0b013e3181e0aa14.

31. Carrier J, Monk TH. Circadian rhythms of performance: new trends. Chronobiol Int. 2009;17:719-32. doi:10.1081/CBI-100102108.

32. Geisler MW, Polich J. P300 and individual differences: morning/evening activity preference, food, and time-of-day. Psychophysiology. 1992;29:86-94. doi:10.1111/j.1469-8986.1992.tb02019.x.

33. Higuchi S, Liu Y, Yuasa T, Maeda A, Motohashi Y. Diurnal variation in the P300 component of human cognitive event-related potential. Chronobiol Int. 2000;17:669-78. doi:10.1081/CBI-100101073.

34. Wesensten NJ, Badia P, Harsh J. Time of day, repeated testing, and interblock interval effects on P300 amplitude. Physiol Behav. 1990;47:653-8. doi:10.1016/0031-9384(90)90073-D.

35. Geisler MW, Polich J. P300 and time of day: Circadian rhythms, food intake, and body temperature. Biol Psychol. 1990;31:117-36. doi:10.1016/0301-0511(90)90012-L.

36. Polich J. EEG and ERP assessment of normal aging. Electroencephalography and Clinical Neurophysiology/Evoked Potentials Section. 1997;104:244-56. doi:10.1016/S0168-5597(97)96139-6.

37. Nordin S, Andersson L, Olofsson JK, McCormack M, Polich J. Evaluation of auditory, visual and olfactory event-related potentials for comparing interspersed- and single-stimulus paradigms. Int J Psychophysiol. 2011;81: 252-62. doi:10.1016/j.ijpsycho.2011.06.020.

38. Nijboer F, Furdea A, Gunst I, Mellinger J, McFarland DJ, Birbaumer N, Kubler A. An auditory brain-computer interface (BCI). J Neurosci Methods. 2008;167: 43-50. doi:10.1016/j.jneumeth.2007.02.009.

39. Mochty U. Sleep, Rapid Eye Movement, and Alertness in Patients with Amyotrophic Lateral Sclerosis [Dissertation]. Tübingen: Universität Tübingen; 2013.

40. Cedarbaum JM, Stambler N, Malta E, Fuller C, Hilt D, Thurmond B, Nakanishi A. The ALSFRS-R: a revised ALS functional rating scale that incorporates assessments of respiratory function. BDNF ALS Study Group (Phase III). J Neurol Sci. 1999;169:13-21.

41. Polich J. P300 from a passive auditory paradigm. Electroencephalogr Clin Neurophysiol. 1989;74:312-20.

42. Duncan-Johnson CC, Donchin E. The P300 component of the event-related brain potential as an index of information processing. Biol Psychol. 1982;14: 1-52. doi:10.1016/0301-0511(82)90016-3. 
43. Semlitsch HV, Anderer $P$, Schuster $P$, Presslich $O$. A solution for reliable and valid reduction of ocular artifacts, applied to the P300 ERP. Psychophysiology. 1986;23:695-703. doi:10.1111/j.1469-8986.1986.tb00696.x.

44. Bakeman R. Recommended effect size statistics for repeated measures designs. Behav Res Methods. 2005;37:379-84. doi:10.3758/BF03192707.

45. Rouder JN, Morey RD, Speckman PL, Province JM. Default Bayes factors for ANOVA designs. J Math Psychol. 2012;56:356-74. doi:10.1016/j.jmp.2012.08.001.

46. Searle SR, Speed FM, Milliken GA. Population marginal means in the linear model: an alternative to least squares means. Am Stat. 1980;34:216. doi:10.2307/2684063.

47. Frigge $M$, Hoaglin DC, Iglewicz B. Some implementations of the boxplot. Am Stat. 1989;43:50. doi:10.2307/2685173.

48. The R Development Core Team. R: A Language and Environment for Statistical Computing. 2010.

49. Lawrence MA. ez: Easy analysis and visualization of factorial experiments for R. 2013

50. Lenth R, Herv M. Least-squares means package for R. 2015.

51. Wheeler B. ImPerm: permutation tests package for R. 2010.

52. Ligges U, Short T, Schnackenberg P, Billinghurst D, Borchers H-W, Carezia A, Dupius P, et al. Signal processing package for R. 2015.

53. Furdea A, Halder S, Krusienski D, Bross D, Nijboer F, Birbaumer N, Kübler A An auditory oddball (P300) spelling system for brain-computer interfaces. Psychophysiology. 2009;46:617-25. doi:10.1111/j.1469-8986.2008.00783.x.

54. Lulé D, Noirhomme Q, Kleih SC, Chatelle C, Halder S, Demertzi A, et al. Probing command following in patients with disorders of consciousness using a brain-computer interface. Clin Neurophysiol. 2013;124:101-6. doi:10. 1016/j.clinph.2012.04.030

55. Laureys S, Faymonville M, Degueldre C, Del Fiore G, Damas PLB, Janssens N, et al. Auditory processing in the vegetative state. Brain. 2000;123:1589-601. doi:10.1093/brain/123.8.1589.

56. Murguialday AR, Hill J, Bensch M, Martens S, Halder S, Nijboer F, et al. Transition from the locked in to the completely locked-in state: a physiological analysis. Clin Neurophysiol. 2011;122:925-33. doi:10.1016/j.clinph.2010.08.019.

57. Halder S, Rea M, Andreoni R, Nijboer F, Hammer E, Kleih S, et al. An auditory oddball brain-computer interface for binary choices. Clin Neurophysiol. 2010;121:516-23. doi:10.1016/j.clinph.2009.11.087.

58. Höhne J, Krenzlin K, Dähne S, Tangermann M. Natural stimuli improve auditory $\mathrm{BCl}$ s with respect to ergonomics and performance. J Neural Eng. 2012;9:45003. doi:10.1088/1741-2560/9/4/045003.

59. Baykara E, Ruf CA, Fioravanti C, Käthner I, Simon N, Kleih SC, et al. Effects of training and motivation on auditory P300 brain-computer interface performance. Clin Neurophysiol. 2016;127:379-87. doi:10.1016/j.clinph.2015.04.054.

60. Pokorny C, Klobassa DS, Pichler G, Erlbeck H, Real RG, Kübler A, et al. The auditory P300-based single-switch brain-computer interface: paradigm transition from healthy subjects to minimally conscious patients. Artif Intell Med. 2013;59:81-90. doi:10.1016/j.artmed.2013.07.003.

61. Pfurtscheller G, Muller-Putz GR, Scherer R, Neuper C. Rehabilitation with brain-computer interface systems. Computer. 2008;41:58-65. doi:10.1109/ MC.2008.432.

62. Silvoni S, Volpato C, Cavinato M, Marchetti M, Priftis K, Merico A, et al. P300based brain-computer interface communication: evaluation and follow-up in amyotrophic lateral sclerosis. Front Neurosci. 2009;3:60. doi:10.3389/neuro. 20.001.2009.

63. Holz EM, Botrel L, Kaufmann T, Kübler A. Long-term independent braincomputer interface home use improves quality of life of a patient in the locked-in state: a case study. Arch Phys Med Rehabil. 2015;96:26. doi:10. 1016/j.apmr.2014.03.035.

64. Sellers EW, Vaughan TM, Wolpaw JR. A brain-computer interface for longterm independent home use. Amyotroph Lateral Scler. 2010;11:449-55. doi:10.3109/17482961003777470.

\section{Submit your next manuscript to BioMed Central and we will help you at every step:}

- We accept pre-submission inquiries

- Our selector tool helps you to find the most relevant journal

- We provide round the clock customer support

- Convenient online submission

- Thorough peer review

- Inclusion in PubMed and all major indexing services

- Maximum visibility for your research

Submit your manuscript at www.biomedcentral.com/submit
Biomed Central 